Article

\title{
Energetic and Exergetic Analysis of a Heat Exchanger Integrated in a Solid Biomass-Fuelled Micro-CHP System with an Ericsson Engine
}

\author{
Marie Creyx ${ }^{1}$, Eric Delacourt ${ }^{1}$, Céline Morin ${ }^{1, *}$, Sylvain Lalot ${ }^{1}$ and Bernard Desmet ${ }^{2}$ \\ 1 LAMIH (UMR CNRS 8201), University of Valenciennes (UVHC), Le Mont Houy, \\ F-59313 Valenciennes Cedex 9, France; marie.creyx@gmail.com (M.C.); \\ eric.delacourt@univ-valenciennes.fr (E.D.); sylvain.lalot@univ-valenciennes.fr (S.L.) \\ 2 ENSIAME (Engineering School), University of Valenciennes (UVHC), Le Mont Houy, \\ F-59313 Valenciennes Cedex 9, France; bernard.desmet@univ-valenciennes.fr \\ * Correspondence: celine.morin@univ-valenciennes.fr; Tel.: +33-3-27-511964; Fax: +33-3-27-511961
}

Academic Editor: Kevin H. Knuth

Received: 22 October 2015; Accepted: 12 April 2016; Published: 20 April 2016

\begin{abstract}
A specific heat exchanger has been developed to transfer heat from flue gas to the working fluid (hot air) of the Ericsson engine of a solid biomass-fuelled micro combined heat and power (CHP). In this paper, the theoretical and experimental energetic analyses of this heat exchanger are compared. The experimental performances are described considering energetic and exergetic parameters, in particular the effectiveness on both hot and cold sides. A new exergetic parameter called the exergetic effectiveness is introduced, which allows a comparison between the real and the ideal heat exchanger considering the Second Law of Thermodynamics. A global analysis of exergetic fluxes in the whole micro-CHP system is presented, showing the repartition of the exergy destruction among the components.
\end{abstract}

Keywords: micro-CHP system; biomass; heat exchanger; energetic and exergetic analysis; exergetic effectiveness

\section{Introduction}

In the current global context, with growing energy consumption, climate change linked to greenhouse gas emissions and limited fossil energy resources, solid biomass-fuelled micro combined heat and electrical power (micro-CHP) systems offer several benefits. In particular, the micro-CHP concept allows primary energy savings (high global efficiency is reached) compared with a separate production of heat and electrical power. The development of such systems also represents a decentralization of the energy production process that limits electrical power transmission and distribution losses.

Solid biomass-fuelled micro-CHP systems are composed of a solid biomass-fuelled boiler and a cogeneration device supplied by means of a heat exchanger to produce mechanical or electrical energy (cf. Figure 1). The literature mentions several solid biomass-fuelled micro-CHP systems associated to various cogeneration devices: a Stirling hot air engine [1-4], an Organic Rankine Cycle (ORC) turbine [5] and a thermoelectric generator [6]. Although no study has dealt with the performances of a solid biomass-fuelled micro-CHP system with an Ericsson hot air engine yet, this cogeneration device is well adapted in such facilities [7]. The Ericsson engine thermal efficiency can reach 52\% [8]. Contrary to other hot air engines, the Ericsson engine does not necessarily require a cold source as it can work with an open cycle as chosen in the present study. In this case, low pressure levels are needed, leading to a less compact engine. 


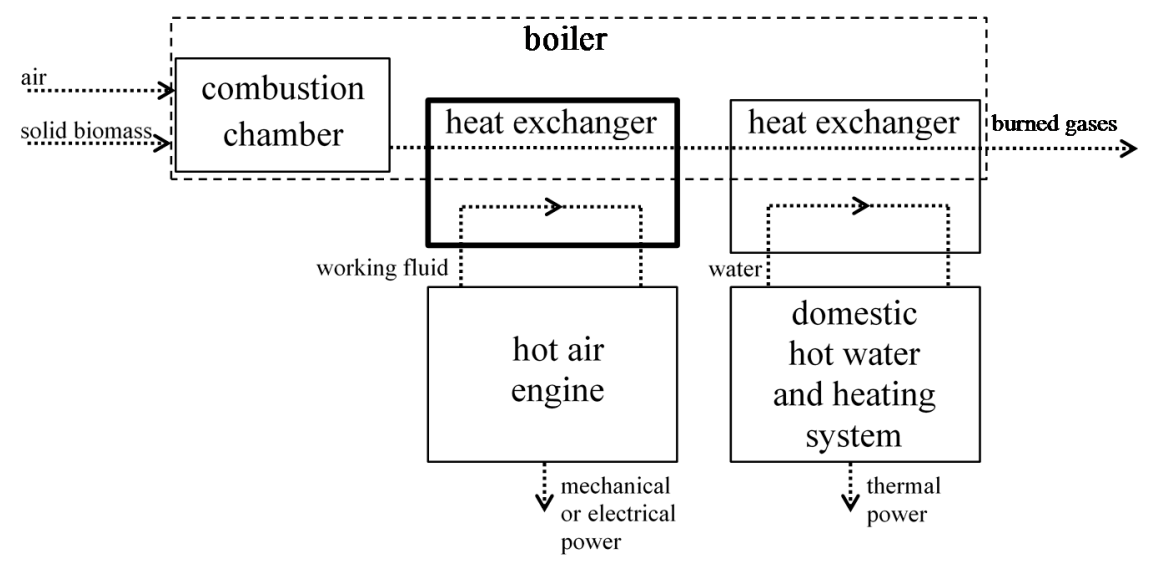

Figure 1. Configuration of solid biomass-fuelled micro-CHP systems.

A biomass-fuelled micro-CHP system with an open cycle Ericsson engine composed of a compression cylinder and an expansion cylinder requires the integration of a specific heat exchanger in the biomass-fuelled boiler to provide hot air to the engine. This heat exchanger encounters strong constraints. The flue gas from biomass combustion presents high temperatures $\left(500\right.$ to $1000{ }^{\circ} \mathrm{C}$ depending on the boiler working conditions) and contains soot particles (1 to $5 \mathrm{ppm}$ ). The volume of the combustion chamber in the boiler is reduced, limiting the volume of the heat exchanger. The air supplying the engine is pressurized (pressure range under 10 bar corresponding to the optimal working conditions of the Ericsson engine). The pressure drops have to be limited on the flue gas side to limit the impact on biomass combustion and on the air side to ensure the high performance of the Ericsson engine.

The gas-gas heat exchangers adapted to flue gas from biomass combustion mentioned in the literature are recuperators supplying micro gas turbines with external combustion [9-11] or tubular heat exchangers associated with Stirling engines $[4,12,13]$. Neither configuration is suited for Ericsson engine supply. The recuperators are designed for high power systems compared with the power required for micro-CHP systems. The tubular heat exchangers developed for Stirling engine supply are very compact and would limit the heat transfer and the performances in the case of a micro-CHP unit with an Ericsson engine. Among high temperature heat exchanger technologies, the multi-tubular heat exchanger with separated tubes appears the most appropriate considering all the constraints.

To determine the working conditions and the performances of the solid biomass-fuelled micro-CHP systems and of their components, an energetic analysis is mostly applied $[1,2,5,6]$. Such studies may be completed with exergetic analyses, following the example presented by [14] with a natural gas micro-CHP system, in order to highlight the zones of exergy destruction and allow an improved optimization of the working conditions to enhance the performances. This approach can be applied in particular to the study of the heat exchanger supplying the Ericsson engine associated to the solid biomass-fuelled micro-CHP system considered. An energetic study of the heat transfer in this heat exchanger, performed with a numerical modelling including the phenomena of conduction, convection and flue gas radiation, is described in [15].

The objectives of the present work are firstly to validate the energetic study [15] with experimental results, and secondly to present an exergetic analysis of the heat exchanger inserted in the solid biomass-fuelled micro-CHP system.

This paper is structured as follows: first, the configuration of the heat exchanger implemented in the micro-CHP system is described. The instrumentation and the experimental methodology are then specified. Energetic and exergetic models of the heat exchanger inserted in the biomass-fuelled micro-CHP facility are presented. Several results (comparison between the energetic study of the heat exchanger and the experimental results, energetic and exergetic performances of the heat exchanger and study of the exergetic fluxes and the exergy destruction in the micro-CHP system) are finally analysed and discussed. 


\section{Configuration of the Heat Exchanger Associated to the Biomass-Fuelled Micro-CHP Unit}

The heat exchanger supplying the Ericsson engine of the biomass-fuelled micro-CHP unit is composed of metallic vertical tubes linked by spacers to form a cylinder (cf. Figure 2). It is a 1-2 heat exchanger: the flue gas flows inside the cylinder (one pass) while the air flows in the tubes (two passes). The heat exchanger is inserted in a domestic biomass-fuelled boiler, in the combustion chamber and above the furnace. The inlet air of the heat exchanger is previously compressed in the compression cylinder of the Ericsson engine. The exhaust air is linked to the expansion cylinder of the Ericsson engine [7]. It has been specifically designed to fit the dimensions of the boiler. It consists of 16 tubes of 21.5 inner diameter, $2 \mathrm{~mm}$ thick, $20 \mathrm{~cm}$ long, located on a $32 \mathrm{~cm}$ diameter circle. They are linked by fins that are welded to the tubes. The whole exchanger is made of $310 \mathrm{~S}$ stainless steel.

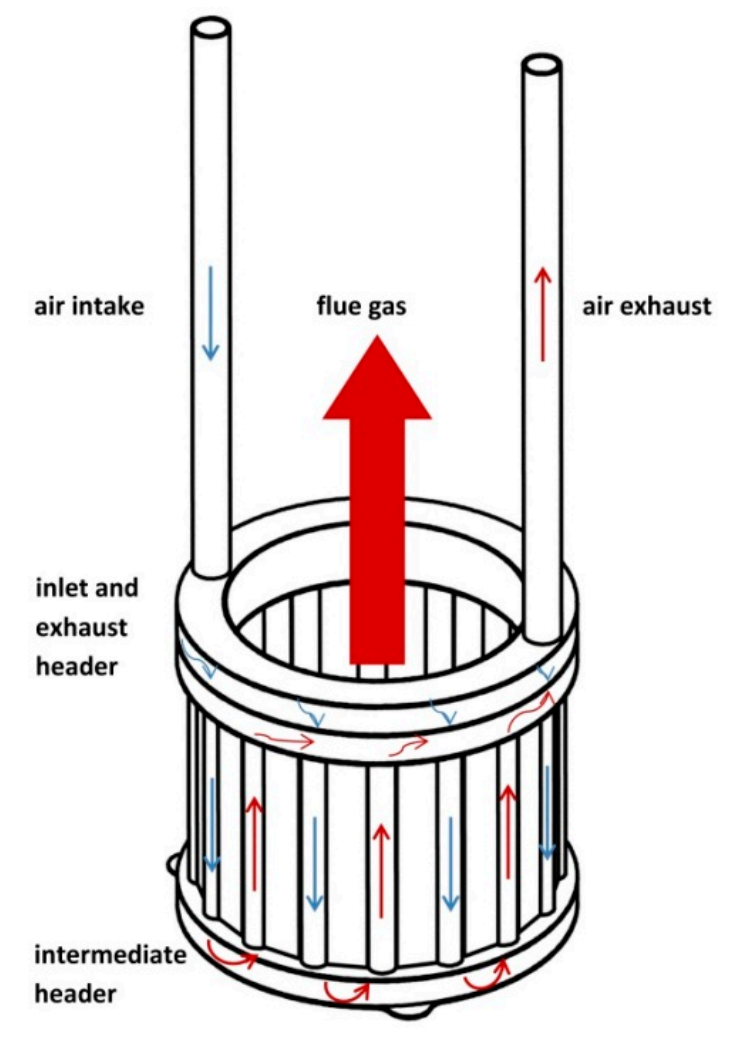

Figure 2. Configuration of the 1-2 heat exchanger.

\section{Materials and Methods}

\subsection{Heat Exchanger Instrumentation: Metrology and Calibration}

The heat exchanger is placed in the cylindrical combustion chamber of the biomass-fuelled boiler. The compression cylinder of the Ericsson engine is simulated using a screw compressor equipped with a manual valve that allows the adjustment of the air mass flow rate entering the heat exchanger. A thermal air mass flow meter (measuring range between 0.2 and $10 \mathrm{Nm}^{3} / \mathrm{h}$, measurement error of $\pm(0.5 \%$ reading data $+0.1 \%$ full scale $))$ is placed at the air inlet of the heat exchanger. An electrical air heater sets the air inlet temperature (up to $760^{\circ} \mathrm{C}$ ). A valve placed at the heat exchanger outlet allows the control of the pressure level (up to 10 bar, precision of $0.04 \%$ of the full scale) in the heat exchanger. As shown in Figure 3, the temperatures of air at the inlet, at the outlet of the heat exchanger, and on the walls at four locations are measured with $0.3 \mathrm{~mm}$ diameter K-type thermocouples (measurement error of $0.75 \%$ ). From the measurements, the wall temperature can be assumed uniform. 


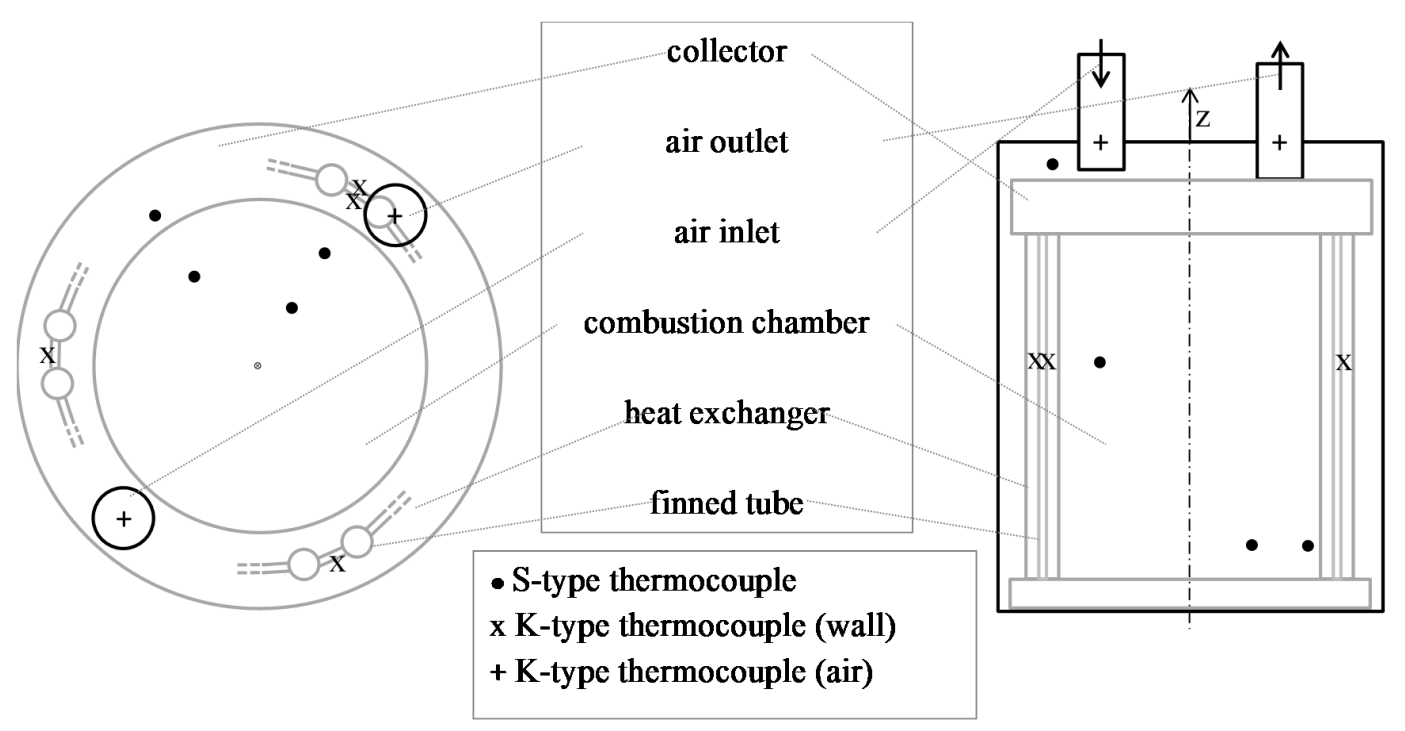

Figure 3. Positions of thermocouples for the heat exchanger tests.

The flue gas temperatures are measured with $0.2 \mathrm{~mm}$ diameter S-type thermocouples (measurement error of $0.25 \%$ ) that can be positioned at several vertical and radial positions (cf. Figure 4 ). To estimate the measurement error linked to radiative flux inside the combustion chamber, the extrapolation method is used: the temperatures are measured simultaneously with two thermocouples of different diameters $(0.2 \mathrm{~mm}$ and $0.13 \mathrm{~mm})$. With a temperature of $600{ }^{\circ} \mathrm{C}$ without correction, the measurement error is estimated to $44^{\circ} \mathrm{C}$ and can reach $187^{\circ} \mathrm{C}$ for a flue gas measured temperature of $1000{ }^{\circ} \mathrm{C}$ (mainly because of the hot junction radiative losses).

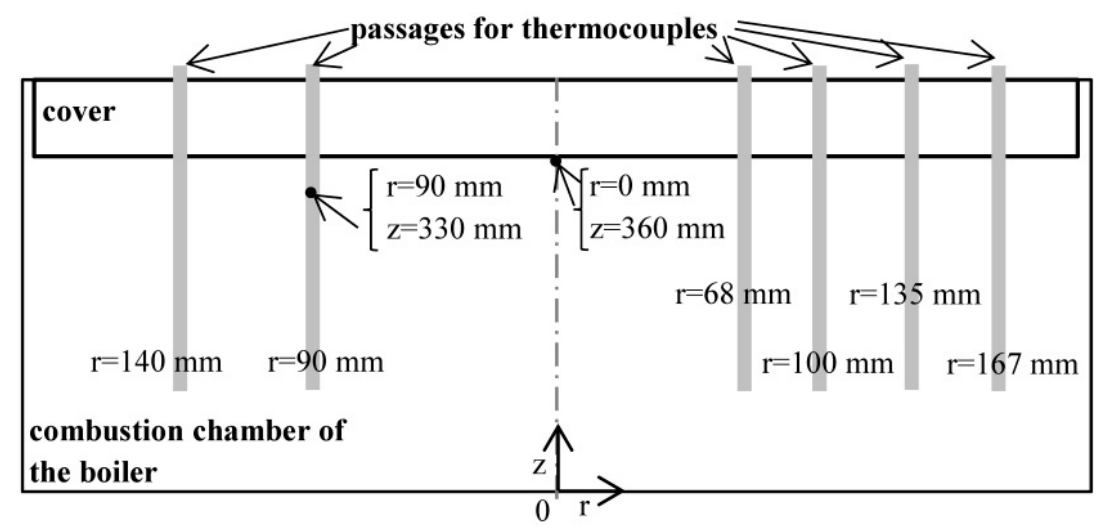

Figure 4. Locations of S-type thermocouples in the combustion chamber (measurement of flue gas temperature).

The flue gas mass flow rate is estimated from the biomass fuel mass flow rate burned and from the combustion equation. The boiler is supplied with wood pellets using a screw conveyor instrumented with a magnetic sensor measuring the angular position. A calibration of the screw links its angular rotation to the mass of pellets supplied in the boiler ( $c f$. Figure 5). From an elementary analysis of wood pellets, the combustion equation is established, considering an air excess $\lambda_{\text {air }}$ of 0.8 [15]:

$$
\begin{aligned}
& \mathrm{C}_{29.93} \mathrm{H}_{45.82} \mathrm{O}_{20.71} \mathrm{~N}_{0.12}+3.42 \mathrm{H}_{2} \mathrm{O}+31.03\left(1+\lambda_{\text {air }}\right)\left(\mathrm{O}_{2}+0.79 / 0.21 \mathrm{~N}_{2}\right) \\
& \rightarrow 29.93 \mathrm{CO}_{2}+26.33 \mathrm{H}_{2} \mathrm{O}+31.03 \lambda_{\text {air }} \mathrm{O}_{2}+31.03\left(1+\lambda_{\text {air }}\right)(0.79 / 0.21) \mathrm{N}_{2}
\end{aligned}
$$

The flue gas mass flow rate is deduced from Equation (1) and from the pellet mass flow rate. 


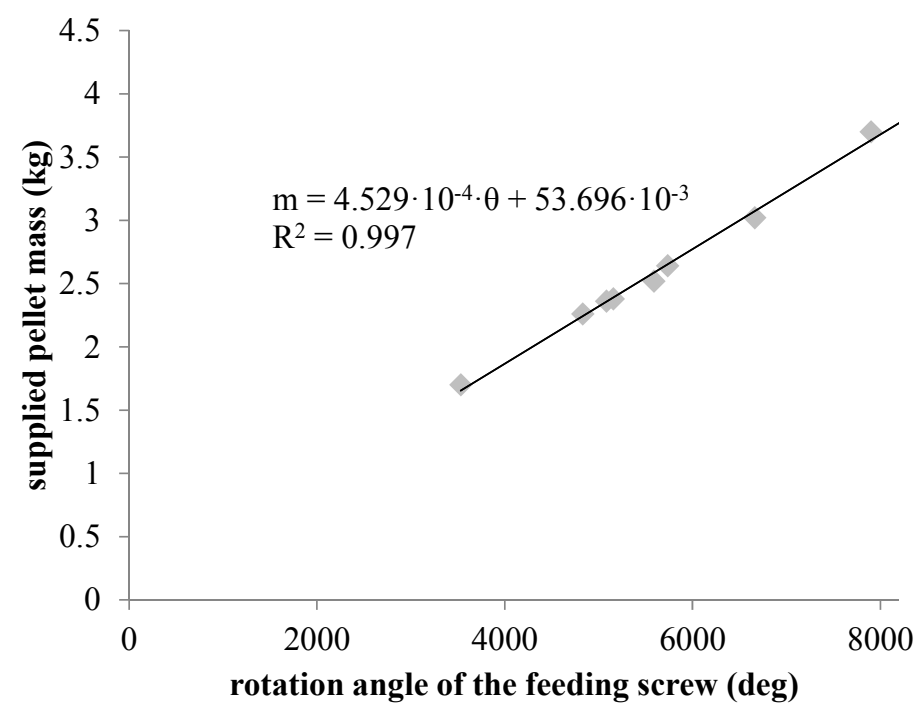

Figure 5. Calibration of the feeding screw of the biomass boiler.

\subsection{Experimental Methodology}

Tests are conducted on the heat exchanger, considering an atmospheric air pressure and various air inlet temperatures and volume flow rates ( $c f$. Table 1). The boiler works in a steady-state. Each test is carried out during $10 \mathrm{~min}$ after a long enough stabilization period.

Table 1. Experimental conditions for the heat exchanger tests.

\begin{tabular}{ccc}
\hline Parameter & Adjusted Value & $\begin{array}{c}\text { Maximum Variation } \\
\text { during a Test of 10 min }\end{array}$ \\
\hline Air volume flow rate & $2.5,5,7.5,10 \mathrm{Nm}^{3} / \mathrm{h}$ & $4.3 \%$ \\
Inlet air temperature & $33,150^{\circ} \mathrm{C}$ & - \\
Inlet flue gas temperature & $818-980^{\circ} \mathrm{C}$ & $9.4 \%$ \\
Test duration & $10 \mathrm{~min}$ & - \\
Sampling frequency & $1 \mathrm{~Hz}$ & - \\
\hline
\end{tabular}

\section{Modelling of the Heat Exchanger Inserted in the Biomass-Fuelled Micro-CHP System}

\subsection{Energetic Model of the Heat Exchanger}

The heat transfer across the heat exchanger inserted in the solid biomass-fuelled boiler of the micro-CHP system depends on several thermal phenomena: conduction, convection and thermal radiation ( $c f$. Figure 6). In particular, the flue gas from solid biomass combustion at high temperature and containing soot particles generates an important thermal radiation and induces fouling on the heat exchanger wall that modifies the conduction through the wall (presence of a soot deposit) [15]. 


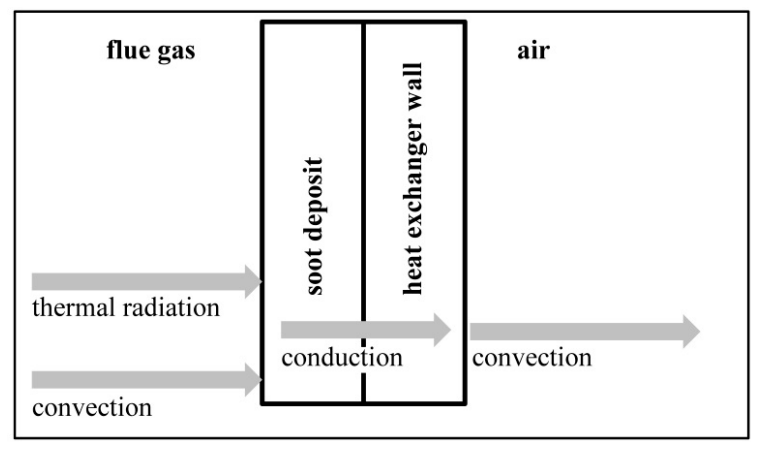

Figure 6. Scheme of the heat transfer phenomena across the heat exchanger.

The Number of Transfer Units method (NTU method) [16] is applied to model the heat exchanger, considering a global heat exchange coefficient evaluated from thermal resistances (convective resistance $R_{c v}$, conductive resistance $R_{c d}$, radiative resistance $R_{R}$ ) [15]. The radiative resistance $R_{R}$ is similar to a convective resistance:

$$
R_{R}=1 /\left(h_{R} A_{g a s}\right)
$$

with $h_{R}$ radiative heat transfer coefficient and $A_{g a s}$ heat exchange surface area in contact with flue gas. The radiative heat transfer coefficient is evaluated by analogy with a convective heat transfer coefficient (hypothesis of a low temperature variation of both air and flue gas flowing through the heat exchanger):

$$
h_{R}=\varphi_{R}\left(T_{\text {gas }}, T_{\text {wall }}\right) /\left(A_{\text {gas }} \cdot\left(\bar{T}_{\text {gas }}-\bar{T}_{\text {wall }}\right)\right)
$$

where $\varphi_{R}\left(T_{\text {gas }}, T_{\text {wall }}\right)$ is the wall radiative heat flux from flue gas depending on flue gas and wall temperatures, $\bar{T}_{\text {gas }}$ and $\bar{T}_{\text {wall }}$ are the flue gas and wall average temperatures. The wall radiative heat flux that depends on flue gas and wall temperatures is evaluated from tabulated values determined by the resolution of the Radiative Transfer Equation (RTE) with a discrete ordinate method [17], considering the model of radiative properties of burned gases (water vapour and carbon dioxide) of [18] and the model of radiative properties of soot particles of [17].

The wall radiative heat flux versus vertical position for several flue gas temperatures and soot volume fractions, in the range $600-1000{ }^{\circ} \mathrm{C}$ and $1-10 \mathrm{ppm}$ respectively, is presented in Figure 7. The wall radiative heat flux increases with temperature and soot volume fraction, with a higher influence of the temperature.

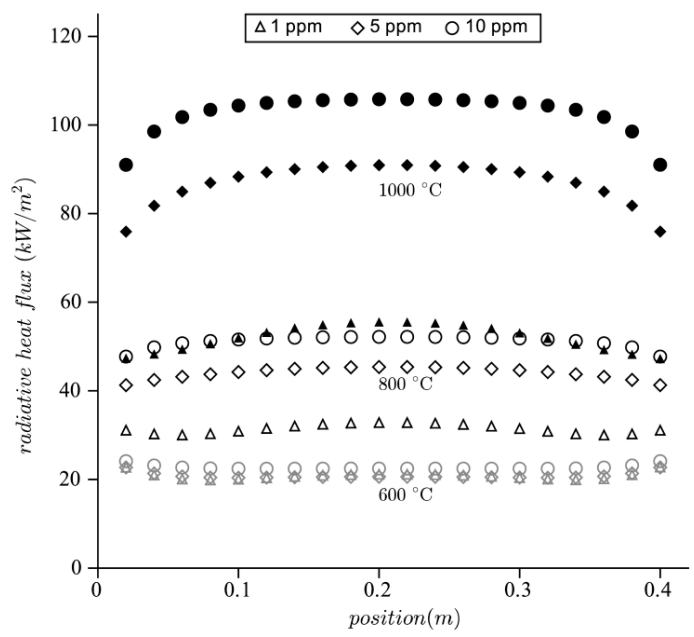

Figure 7. Evolution of the radiative heat flux versus the position for different flue gas temperatures and soot volume fractions. 
In the heat exchanger, the hot fluid (subscript h) flowing with one pass (subscript 1 ) is the flue gas. The cold fluid (subscript c) flowing with two passes (subscript 2) is air. Applying the NTU method requires the evaluation of the heat capacity ratio $R_{h}$ on the side of hot fluid, of the effectiveness $E_{h}$ and $E_{c}$ on the sides of hot and cold fluids respectively, of the Number of Transfer Units of a 1-2 heat exchanger with inlets on opposite sides $N T U_{1,1-2}$ and of the Number of Transfer Units of a heat exchanger on the sides of hot and cold fluids $N T U_{h}$ and $N T U_{c}$ respectively. The equations are detailed in the following:

$$
R_{h}=\frac{\dot{m}_{h} c_{h}}{\dot{m}_{c} \mathcal{c}_{c}}
$$

with $\dot{m}_{h}$ and $\dot{m}_{c}$ hot and cold fluid mass flow rates respectively, $c_{h}$ and $c_{c}$ hot and cold fluid heat capacities at constant pressure respectively:

$$
E_{h}=\left(T_{h, \text { in }}-T_{h, e x}\right) /\left(T_{h, \text { in }}-T_{c, \text { in }}\right)
$$

with $T_{h, i n}, T_{h, e x}$ the hot fluid inlet and exhaust temperatures, $T_{c, \text { in }}$ the cold fluid inlet temperature:

$$
E_{c}=\left(T_{c, e x}-T_{c, i n}\right) /\left(T_{h, \text { in }}-T_{c, i n}\right)
$$

with $T_{\mathcal{c}, e x}$ the cold fluid exhaust temperature:

$$
N T U_{1,1-2}=\frac{1}{\sqrt{1+R_{1}^{2}}} \ln \left(1+\frac{\sqrt{1+R_{1}^{2}}}{\frac{1}{E_{1}}-\frac{R_{1}}{2}-\frac{1+\sqrt{1+R_{1}^{2}}}{2}}\right)
$$

with subscript 1 corresponding to the one pass fluid. Here the flue gas is the fluid flowing with one pass and is also the hot fluid, so that the $N T U_{1,1-2}$ equals the $N T U_{h}$ :

$$
N T U_{h}=U_{A} A /\left(\dot{m}_{h} c_{h}\right)
$$

with $U_{A}$ the global heat transfer coefficient and $A$ the reference heat exchange surface area:

$$
N T U_{c}=R_{h} N T U_{h}
$$

\subsection{Exergetic Model of the Heat Exchanger Inserted in the Biomass-Fuelled Micro-CHP System}

The components of the micro-CHP system ( $c f$. Figure 1) investigated in the exergetic analysis are the following: combustion chamber (comb), heat exchanger (Ha) supplying the cogeneration system, heat exchanger $(\mathrm{Hw})$ supplying the domestic heating system, Ericsson engine used as a cogeneration system (coge) (cf. Figure 8).

The domestic heating system is not modelled in the exergetic analysis. For each component, the exergy fluxes $\dot{E} x$ linked to intake (in) and exhaust (ex) fluids, to wall heat losses and to mechanical power transferred are evaluated. The exergy fluxes $\dot{E} x$ exchanged in the micro-CHP system with the combustion chamber (comb), the gas-air heat exchanger (Ha), the gas-water heat exchanger $(\mathrm{Hw})$, the cogeneration Ericsson engine (coge) are detailed in Figure 8, considering several phenomena: mass transfer, heat transfer $(\dot{E} x \dot{\mathrm{Q}})$ and mechanical power produced $\left(\dot{E} x^{\dot{W}}\right)$. The fluids (air, biomass fuel, gas, water) are indicated in the following figure for the intake (in) and the exhaust (ex) of each element. 


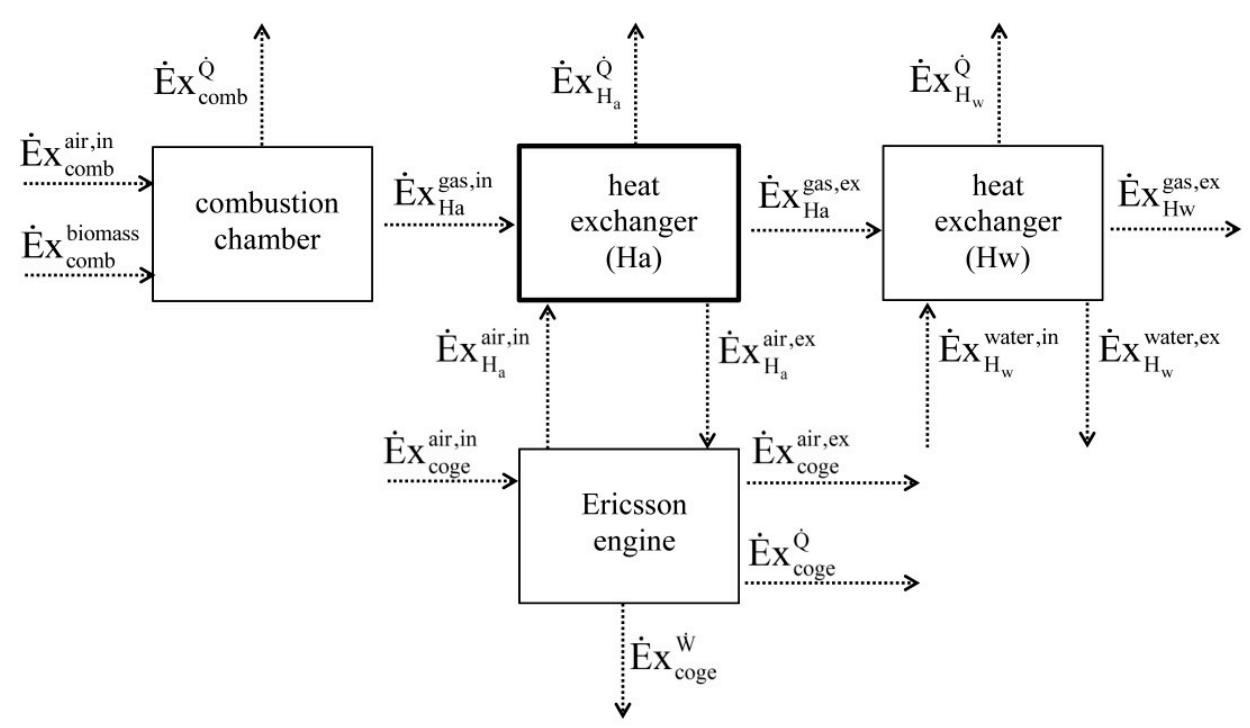

Figure 8. Exergy exchanges in the solid biomass-fuelled micro-CHP system.

\subsubsection{Exergetic Balances}

An exergetic balance applied to the combustion part allows the evaluation of the exergy destruction in the boiler furnace $\dot{E} x_{\text {comb }}^{\text {destr }}$ :

$$
\dot{E} x_{c o m b}^{a i r, \text { in }}+\dot{E} x_{\text {comb }}^{\text {biomass }}-\dot{E} x_{H a}^{g a s, \text { in }}=\underbrace{-\left(\dot{Q}_{c o m b}-\iint_{A_{w, \text { comb }}} \frac{T_{a}}{T_{w, \text { comb }}} \delta \dot{q}_{\text {comb }}\right)-T_{a} \dot{S}_{\text {gen, comb }}}_{\dot{E} x_{\text {comb }}^{\text {destr }}}
$$

with $\dot{E} x_{\text {comb }}^{a i r, i n}, \dot{E} x_{\text {comb }}^{\text {biomass }}$ and $\dot{E} x_{\mathrm{Ha}}^{\text {gas,in }}$ the exergy fluxes of intake air, biomass fuel and exhaust flue gas of the furnace respectively, $\dot{Q}_{c o m b}$ and $\dot{q}_{c o m b}$ the thermal power and the heat flux density transmitted through the boiler wall respectively, $T_{a}$ the ambient temperature, $T_{w, c o m b}$ the furnace wall temperature, $A_{w, \text { comb }}$ the furnace wall surface, $\dot{S}_{\text {gen,comb }}$ the entropy flux generated in the furnace. In the same way, the exergy destruction in the heat exchangers (Ha) and (Hw), respectively $\dot{E} x_{H a}^{d e s t r}$ and $\dot{E} x_{H w}^{d e s t r}$, and in the Ericsson engine $\dot{E} x_{\text {coge }}^{\text {destr }}$ can be evaluated from exergy balances:

$$
\dot{E} x_{H a}^{d e s t r}=\left(\dot{E} x_{H a}^{g a s, i n}-\dot{E} x_{H a}^{g a s, e x}\right)-\left(\dot{E} x_{H a}^{a i r, e x}-\dot{E} x_{H a}^{a i r, i n}\right)
$$

with $\dot{E} x_{\mathrm{Ha}}^{g a s, i n}$ and $\dot{E} x_{\mathrm{Ha}}^{g a s, e x}$ the exergy fluxes of the intake and exhaust flue gas of the heat exchanger Ha respectively, $\dot{E} x_{\mathrm{Ha}}^{\mathrm{air}, \mathrm{in}}$ and $\dot{\mathrm{E}} x_{\mathrm{Ha}}^{\mathrm{air}, e x}$ the exergy fluxes of the intake and exhaust air of the heat exchanger Ha, respectively:

$$
\dot{E} x_{H w}^{d e s t r}=\left(\dot{E} x_{H a}^{g a s, e x}-\dot{E} x_{H w}^{g a s, e x}\right)-\left(\dot{E} x_{H w}^{w a t e r, e x}-\dot{E} x_{H w}^{w a t e r, i n}\right)
$$

with $\dot{E} x_{H a}^{g a s, e x}$ the exergy flux of the flue gas entering the heat exchanger $\mathrm{Hw}$ (coming from the exhaust of the heat exchanger Ha), $\dot{E} x_{H w}^{g a s, e x}$ the exergy flux of the flue gas at the exhaust of the heat exchanger $\mathrm{Hw}, \dot{E} x_{\mathrm{Hw}}^{\text {water, in }}$ and $\dot{E} x_{\mathrm{Hw}}^{\text {water,ex }}$ the exergy fluxes of the intake and exhaust water of the heat exchanger Hw, respectively: 


$$
\dot{E} x_{\text {coge }}^{a i r, i n}-\dot{E} x_{H a}^{a i r, i n}+\dot{E} x_{H a}^{a i r, e x}-\dot{E} x_{\text {coge }}^{a i r, e x}-\dot{E} x_{\text {coge }}^{\dot{W}}=\underbrace{-\left(\dot{Q}_{\text {coge }}-\iint_{A_{w, \text { coge }}} \frac{T_{a}}{T_{w, \text { coge }}} \delta \dot{q}_{\text {coge }}\right)-T_{a} \dot{S}_{\text {gen,coge }}}_{\dot{E} x_{\text {coge }}^{\text {destr }}}
$$

with $\dot{E} x_{\text {coge }}^{a i r, i n}$ the exergy flux of the intake air of the Ericsson engine from the atmosphere, $\dot{E} x_{H a}^{a i r, i n}$ the exergy flux of compressed air leaving the Ericsson engine and entering the air heat exchanger $\mathrm{Ha}$, $\dot{E} x_{\mathrm{Ha}}^{a i r}, \mathrm{x}$ the exergy flux entering the Ericsson engine and coming from the exhaust of the heat exchanger Ha, $\dot{E} x_{\text {coge }}^{\text {air,ex }}$ the exergy flux at the exhaust of the Ericsson engine, $\dot{E} x_{\text {comb }}^{\dot{W}}$ the exergy flux linked to effective mechanical power produced, $\dot{Q}_{\text {coge }}$ and $\dot{q}_{\text {coge }}$ the thermal power and the heat flux density transmitted through the wall of the Ericsson engine respectively, $T_{w, \text { coge }}$ the wall temperature of the Ericsson engine, $A_{w, \text { coge }}$ the wall surface of the Ericsson engine, $\dot{S}_{g e n, \text { coge }}$ the entropy flux generated in the Ericsson engine.

The exergy destruction $\dot{E} x^{\text {destr }}$ evaluated in Equations (10)-(13) is then expressed with two terms. The first term is linked to a heat transfer through the wall of the component considered, the second term is linked to generated entropy.

\subsubsection{Exergy Flux of Solid Biomass Fuel}

Contrary to the exergy fluxes of air and flue gas (that can be calculated with the specific enthalpy and specific entropy variations of the gases from reference conditions [19]), the exergy flux of a fuel requires the evaluation of its specific chemical exergy (thermal exergy released by chemical reactions until reaching an equilibrium state compared with the chemical composition of the environment), which is linked to the chemical process of combustion.

For solid biomass fuels, the specific chemical exergy cannot be evaluated from thermodynamic equations, as for common gas and liquid fuels, due to a lack of the necessary thermodynamic data (specific enthalpy, entropy and chemical potential of solid biomass fuels depending on thermodynamic conditions). Several methods are mentioned in the literature to evaluate the specific chemical exergy of solid biomass fuels [20-24]. They are based on experimental correlations taking into account the lower heating value of the biomass fuel [20-24], the elementary composition [20,24], the ash quantity [20,23,24], the humidity of the fuel [23], the presence of sulphur [23]. For the wood pellets used here, an experimental elementary analysis of the composition including the humidity (cf. Equation (1)) and an experimental evaluation of the lower heating value $(17,900 \mathrm{~kJ} / \mathrm{kg})$ are established. In this study, the specific chemical exergy of pellets considered is evaluated with the correlation of Szargut [23] and reaches $20,495 \mathrm{~kJ} / \mathrm{kg}$.

4.2.3. Exergetic Performances of the Heat Exchanger Ha: Exergetic Efficiency and Exergetic Effectiveness

The exergetic efficiency of the heat exchanger is evaluated as follows:

$$
\eta_{e x, H a}=\frac{\dot{E} x_{H a}^{a i r, e x}-\dot{E} x_{H a}^{a i r, i n}}{\dot{E} x_{H a}^{g a s, i n}-\dot{E} x_{H a}^{g a s, e x}}
$$

It corresponds to the ratio between the exergetic flux received by the cold fluid and the exergetic flux lost by the hot fluid.

In the NTU method, the real heat exchanger is compared to an ideal heat exchanger corresponding to the case where the hot fluid exhaust temperature equals the cold fluid inlet temperature (effectiveness evaluated on the side of hot fluid, $c f$. Equation (5)) or to the case where the cold fluid outlet temperature reaches the hot fluid inlet temperature (effectiveness evaluated on the side of cold fluid, 
$c f$. Equation (6)), considering the First Law of Thermodynamics. A similar comparison between real and ideal heat exchangers can be applied considering the Second Law of Thermodynamics. The ideal heat exchanger is defined, for the hot side, as the heat exchanger that would lead to a hot side outlet temperature equal to the cold side inlet temperature. Similarly, the ideal heat exchanger is defined, for the cold side, as the heat exchanger that would lead to a cold side outlet temperature equal to the hot side inlet temperature. Wu et al. [25] introduced exergy transfer effectiveness to describe the performance of heat exchangers and compared it with heat transfer effectiveness.

In our study, the exergetic effectiveness on the side of hot fluid $E_{e x_{h}}$ is defined as:

$$
E_{e x_{h}}=\frac{\dot{m}_{h}\left[\left(h_{h}\left(T_{h, i n}\right)-T_{a} \cdot s_{h}\left(T_{h, i n}\right)\right)-\left(h_{h}\left(T_{h, e x}\right)-T_{a} \cdot s_{h}\left(T_{h, e x}\right)\right)\right]}{\dot{m}_{h}\left[\left(h_{h}\left(T_{h, i n}\right)-T_{a} \cdot s_{h}\left(T_{h, i n}\right)\right)-\left(h_{h}\left(T_{c, i n}\right)-T_{a} \cdot s_{h}\left(T_{c, i n}\right)\right)\right]}
$$

with $h_{h}$ and $s_{h}$ respectively specific enthalpy and entropy of hot fluid, $T_{h, i n}, T_{h, \text { ex }}$ respectively inlet and exhaust hot fluid temperatures, $T_{c, i n}$ inlet cold fluid temperature.

This exergetic effectiveness corresponds to the ratio between the real exergetic flux transferred from the hot fluid, i.e., the potentially recoverable mechanical power, and the mechanical power that would have been recoverable by taking the hot fluid to the cold fluid inlet temperature.

The exergetic effectiveness on the side of cold fluid $E_{e x_{c}}$ is written:

$$
E_{e x_{c}}=\frac{\dot{m}_{c}\left[\left(h_{c}\left(T_{c, e x}\right)-T_{a} \cdot s_{c}\left(T_{c, e x}\right)\right)-\left(h_{c}\left(T_{c, i n}\right)-T_{a} \cdot s_{c}\left(T_{c, i n}\right)\right)\right]}{\dot{m}_{c}\left[\left(h_{c}\left(T_{h, i n}\right)-T_{a} \cdot s_{c}\left(T_{h, i n}\right)\right)-\left(h_{c}\left(T_{c, i n}\right)-T_{a} \cdot s_{c}\left(T_{c, i n}\right)\right)\right]}
$$

with $h_{c}$ and $s_{c}$ respectively specific enthalpy and entropy of cold fluid, $T_{c, e x}$ exhaust cold fluid temperature.

This exergetic effectiveness corresponds to the real gain of the exergetic flux from the cold fluid, i.e., the potentially gain of the mechanical power that can be supplied by the cold fluid, compared to the gain that could be obtained by taking the cold fluid to the hot fluid inlet temperature.

\section{Results and Discussion}

A comparison of the theoretical and experimental characterization of the heat exchanger supplying the cogeneration system is conducted. The performances achieved are detailed. An analysis of the exergetic fluxes in the micro-CHP system is presented. In the following, the ambient temperature considered, in particular for exergetic analyses, is $293 \mathrm{~K}$.

\subsection{Energetic Study of the Heat Exchanger: Comparison of Theoretical and Experimental Results}

An experimental characterization of the heat exchanger supplying the Ericsson engine is conducted following the procedures described in Section 3. The inlet and exhaust temperatures of flue gas and air and the temperature of the heat exchanger wall are measured for different air volume flow rates crossing the heat exchanger, two inlet air temperatures of $33^{\circ} \mathrm{C}$ and $150{ }^{\circ} \mathrm{C}$, and various gas inlet temperatures. From the temperatures measured, the experimental thermal power exchanged $P_{\text {th }}$ can be estimated with the following equation:

$$
P_{\text {th }}=\dot{m}_{\text {air }} c_{\text {air }}\left(T_{\text {air }, e x}-T_{\text {air, in }}\right)
$$

with $c_{a i r}$ the heat capacity at constant pressure and at average temperature of air. The results are given in Table 2. 
Table 2. Experimental values for the heat exchanger tests.

\begin{tabular}{|c|c|c|c|c|c|c|c|c|}
\hline \multirow{2}{*}{$\begin{array}{c}\text { Air Flow Rate } \\
\text { Inlet air temperature }\end{array}$} & \multicolumn{2}{|c|}{$2.5 \mathrm{Nm}^{3} / \mathrm{h}$} & \multicolumn{2}{|c|}{$5 \mathrm{Nm}^{3} / \mathrm{h}$} & \multicolumn{2}{|c|}{$7.5 \mathrm{Nm}^{3} / \mathrm{h}$} & \multicolumn{2}{|c|}{$10 \mathrm{Nm}^{3} / \mathrm{h}$} \\
\hline & $33^{\circ} \mathrm{C}$ & $150^{\circ} \mathrm{C}$ & $33^{\circ} \mathrm{C}$ & $150{ }^{\circ} \mathrm{C}$ & $33^{\circ} \mathrm{C}$ & $150^{\circ} \mathrm{C}$ & $33^{\circ} \mathrm{C}$ & $150^{\circ} \mathrm{C}$ \\
\hline Inlet flue gas temperature & $980^{\circ} \mathrm{C}$ & $818^{\circ} \mathrm{C}$ & $955^{\circ} \mathrm{C}$ & $870{ }^{\circ} \mathrm{C}$ & $954^{\circ} \mathrm{C}$ & $904^{\circ} \mathrm{C}$ & $924^{\circ} \mathrm{C}$ & $962{ }^{\circ} \mathrm{C}$ \\
\hline Wall temperature & $737^{\circ} \mathrm{C}$ & $638^{\circ} \mathrm{C}$ & $729^{\circ} \mathrm{C}$ & $666^{\circ} \mathrm{C}$ & $719^{\circ} \mathrm{C}$ & $684^{\circ} \mathrm{C}$ & $693^{\circ} \mathrm{C}$ & $717^{\circ} \mathrm{C}$ \\
\hline Outlet air temperature & $232{ }^{\circ} \mathrm{C}$ & $194^{\circ} \mathrm{C}$ & $294^{\circ} \mathrm{C}$ & $257^{\circ} \mathrm{C}$ & $325^{\circ} \mathrm{C}$ & $294^{\circ} \mathrm{C}$ & $319^{\circ} \mathrm{C}$ & $336^{\circ} \mathrm{C}$ \\
\hline Outlet flue gas temperature & $936^{\circ} \mathrm{C}$ & $770^{\circ} \mathrm{C}$ & $930^{\circ} \mathrm{C}$ & $818^{\circ} \mathrm{C}$ & $914^{\circ} \mathrm{C}$ & $846^{\circ} \mathrm{C}$ & $894^{\circ} \mathrm{C}$ & $897^{\circ} \mathrm{C}$ \\
\hline Thermal power & $182 \mathrm{~W}$ & $68 \mathrm{~W}$ & $506 \mathrm{~W}$ & $189 \mathrm{~W}$ & $848 \mathrm{~W}$ & $410 \mathrm{~W}$ & $1096 \mathrm{~W}$ & $719 \mathrm{~W}$ \\
\hline
\end{tabular}

The wall temperature $T_{\text {wall }}$ follows the same evolution as the inlet flue gas temperature $T_{\text {gas, in }}$ obtained during the tests for different air volume flow rates. The exhaust air temperature $T_{\text {air }, e x}$ increases with the air volume flow rate. This shows that the increase of the air velocity has a direct impact on the global heat transfer, despite the flue gas inlet temperature variations. During the tests, the exhaust air temperature is lower when the air is preheated via $6 \mathrm{~kW}$ electrical heating than without preheating. This contradictory result is caused by a higher influence of the flue gas inlet temperature on the global heat exchange compared with the inlet air temperature.

The thermal power increases with the air volume flow rate and with the gas inlet temperature. In the same way as the air exhaust temperature, the thermal power exchanged is lower for the tests when the air inlet is preheated, but the inlet flue gas temperature is lower, showing the higher impact on the heat transfer of the inlet flue gas temperature compared with the inlet air temperature.

The experimental convective heat transfer coefficient between the heat exchanger wall and the air flow $h_{a i r, c v}$ can be defined as:

$$
h_{\text {air,co }}=P_{\text {th }} /\left(A_{\text {air }}\left(T_{\text {wall }}-\bar{T}_{\text {air }}\right)\right)
$$

with $A_{\text {air }}$ the heat exchanger wall surface area on the side of air (reference surface assumed), $T_{\text {wall }}$ the temperature of heat exchanger wall, $\bar{T}_{\text {air }}$ the average air temperature in the heat exchanger. In the same way, the experimental convective and radiative heat transfer coefficient between the heat exchanger wall and the flue gas $h_{g a s, c v-R}$ is written:

$$
h_{g a s, c v-R}=P_{t h} /\left(A_{\text {air }}\left(\bar{T}_{g a s}-T_{\text {wall }}\right)\right)
$$

with $\bar{T}_{g a s}$ the average flue gas temperature in the heat exchanger. The experimental heat transfer coefficients of Equations (19) and (20) depending on air volume flow rate for several inlet air temperatures are presented in Figure 9. The convective heat transfer coefficient on the side of air is lower than the convective and radiative heat transfer coefficient on the side of flue gas, so that the convection phenomenon between the heat exchanger wall and the air is the first limitation to the global heat transfer in the heat exchanger. This result corroborates the conclusions of the energetic study of the heat exchanger presented in [15]. 


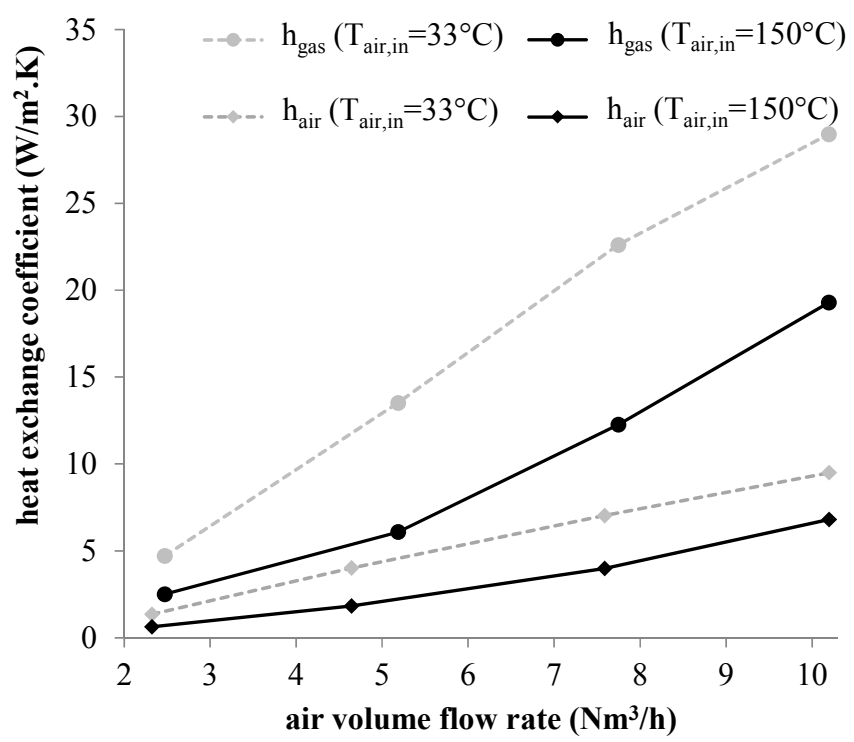

Figure 9. Evolution of the convective heat transfer coefficient of air $h_{\text {air }}$ and of the convective and radiative heat transfer coefficient of flue gas $h_{g a s}$ versus air volume flow rate for air inlet temperatures of $33^{\circ} \mathrm{C}$ and $150{ }^{\circ} \mathrm{C}$.

It is important to know if the design of the heat exchanger leads to the possible application of the NTU-Effectiveness method. For example, it is necessary to check that the design of the headers does not lead to flow maldistribution that are known to decrease the effectiveness of any heat exchanger [26]. Hence, it is necessary to estimate the global heat transfer coefficient by another method: the log mean temperature difference. The thermal power is written:

$$
P=F U A \Delta T_{\log }=F U A \frac{\left(T_{g a s, i n}-T_{a i r, e x}\right)-\left(T_{\text {gas }, e x}-T_{a i r, i n}\right)}{\ln \left(\frac{T_{\text {gas }, i n}-T_{\text {air }, e x}}{T_{\text {gas }, e x}-T_{\text {ari }, \text { in }}}\right)}
$$

It is possible to introduce the average temperatures:

$$
P=F U A \frac{\left(\bar{T}_{g a s}+\Delta T_{g a s, i n}-\left(\bar{T}_{a i r}+\Delta T_{a i r, e x}\right)\right)-\left(\bar{T}_{g a s}-\Delta T_{g a s, e x}-\left(\bar{T}_{a i r}-\Delta T_{a i r, i n}\right)\right)}{\ln \left(\frac{\bar{T}_{\text {gas }}+\Delta T_{\text {gas }, \text { in }}-\left(\bar{T}_{\text {air }}+\Delta T_{\text {air }, e x}\right)}{\bar{T}_{\text {gas }}-\Delta T_{\text {gas }, e x}-\left(\bar{T}_{\text {air }}-\Delta T_{\text {air }, \text { in }}\right)}\right)}
$$

where the temperature drops or gains are defined as follows: $T_{\text {gas }, \text { in }}=\bar{T}_{\text {gas }}+\Delta T_{\text {gas,in }}, T_{\text {gas,out }}=$ $\bar{T}_{\text {gas }}-\Delta T_{\text {gas,ex }}, T_{a i r, i n}=\bar{T}_{a i r}-\Delta T_{a i r, i n}, T_{a i r, e x}=\bar{T}_{a i r}+\Delta T_{a i r, e x}$. This equation can be simplified:

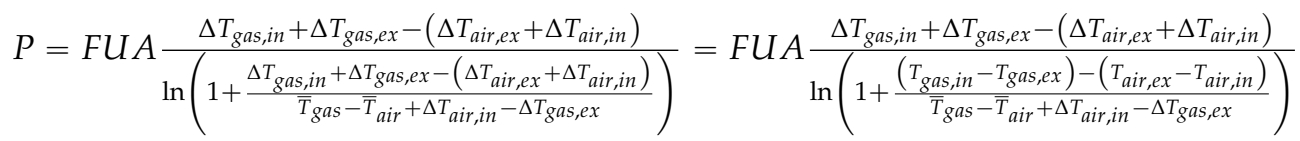

If the temperature differences $\left(T_{a i r, e x}-T_{a i r, i n}\right)$ and $\left(T_{g a s, \text { in }}-T_{g a s, e x}\right)$ are much smaller than the difference of the mean temperatures $\left(\bar{T}_{\text {gas }}-\bar{T}_{\text {air }}\right)$, it can be assumed that:

$$
\ln \left(1+\frac{\Delta T_{g a s, \text { in }}+\Delta T_{\text {gas }, e x}-\left(\Delta T_{a i r, e x}+\Delta T_{a i r, \text { in }}\right)}{\bar{T}_{\text {gas }}-\bar{T}_{\text {air }}+\Delta T_{\text {air }, \text { in }}-\Delta T_{\text {gas }, e x}}\right) \approx \frac{\Delta T_{\text {gas }, \text { in }}+\Delta T_{\text {gas }, e x}-\left(\Delta T_{\text {air }, \text { ex }}+\Delta T_{\text {air }, \text { in }}\right)}{\bar{T}_{\text {gas }}-\bar{T}_{\text {air }}+\Delta T_{\text {air }, \text { in }}-\Delta T_{\text {gas }, \text { ex }}}
$$

and Equation (22) reduces to:

$$
P=F U A\left(\bar{T}_{\text {gas }}-\bar{T}_{a i r}+\Delta T_{\text {air }, \text { in }}-\Delta T_{\text {gas,ex }}\right) \approx F U A\left(\bar{T}_{\text {gas }}-\bar{T}_{\text {air }}\right)
$$


The correction factor depends on the $P_{c}$ and $R_{c}$ factors [27] (cf. Table 3).

Table 3. Experimental values of the $P_{c}$ and $R_{c}$ factors.

\begin{tabular}{|c|c|c|c|c|c|c|c|c|}
\hline \multirow{2}{*}{$\frac{\text { Air Flow Rate }}{P_{\mathcal{C}}}$} & \multicolumn{2}{|c|}{$2.5 \mathrm{Nm}^{3} / \mathrm{h}$} & \multicolumn{2}{|c|}{$5 \mathrm{Nm}^{3} / \mathrm{h}$} & \multicolumn{2}{|c|}{$7.5 \mathrm{Nm}^{3} / \mathrm{h}$} & \multicolumn{2}{|c|}{$10 \mathrm{Nm}^{3} / \mathrm{h}$} \\
\hline & 0.21 & 0.066 & 0.28 & 0.14 & 0.32 & 0.19 & 0.32 & 0.23 \\
\hline$R_{c}$ & 0.22 & 1.1 & 0.096 & 0.49 & 0.14 & 0.40 & 0.10 & 0.35 \\
\hline
\end{tabular}

It can be concluded that in all experimental conditions, the correction factor is unity. Hence, the thermal power transmitted across the heat exchanger can be approximated by $P_{\text {th }}=U_{\text {approximate }} A_{\text {air }}\left(\bar{T}_{\text {gas }}-\bar{T}_{\text {air }}\right)$. Inserting Equation (18) in this equation leads to an estimation of the global heat exchange coefficient:

$$
U_{\text {approximate }}=\frac{\dot{m}_{\text {air }} c_{\text {air }}\left(T_{\text {air }, \text { ex }}-T_{\text {air, } i n}\right)}{A_{\text {air }}\left(\bar{T}_{\text {gas }}-\bar{T}_{\text {air }}\right)}
$$

The experimental global heat exchange coefficient can also be evaluated using the Number of Transfer Units of Section 4.1:

$$
U_{N T U}=\left(N T U_{c} \dot{m}_{\text {air }} c_{\text {air }}\right) / A_{\text {air }}
$$

The experimental global heat exchange coefficients evaluated with Equations (20) and (26), depending on the air volume flow rate for several air inlet temperatures, are represented in Figure 10. The results are superposed, that shows the appropriateness of the NTU method to study the heat transfer through the heat exchanger, even when a radiative heat transfer from flue gas occurs and that justifies also the approximation used for the estimation of $U_{\text {approximate. }}$ The influence of the air volume flow rate and of the inlet air temperature on the global heat exchange coefficient is similar as on the thermal power exchanged ( $c f$. Table 2). The global heat exchange coefficient is situated between 0.47 and $6.8 \mathrm{~W} / \mathrm{m}^{2} \cdot \mathrm{K}$ for the studied range of air volume flow rates. This low value is linked to the low air volume flow rate in the heat exchanger for a large flow section, which leads to a laminar flow of air and to a limited convective heat exchange between air and heat exchanger wall (cf. Figure 9).

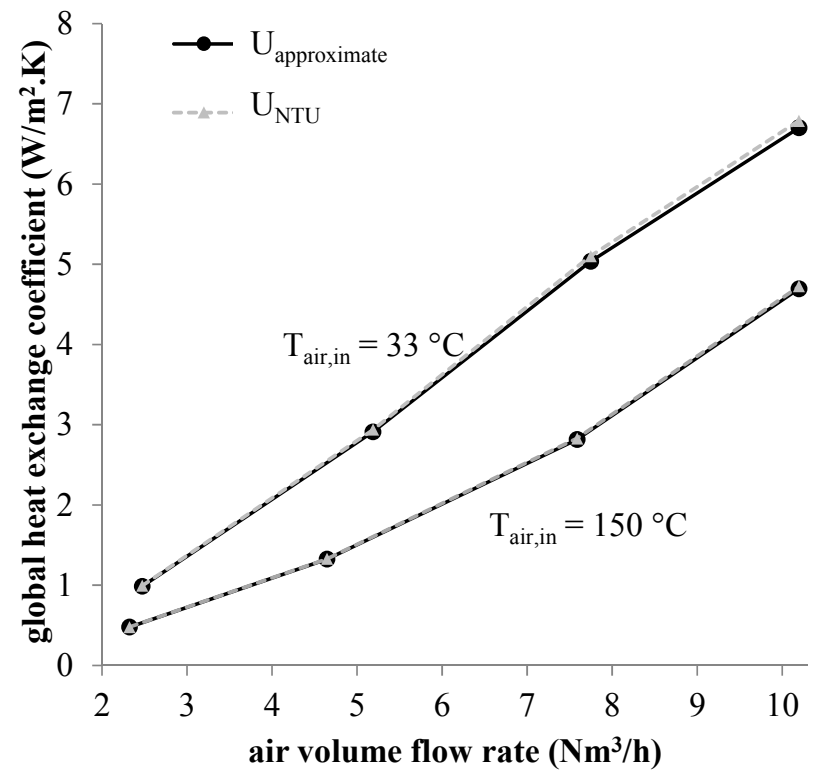

Figure 10. Comparison of the experimental global heat exchange coefficient evaluated from First Law of Thermodynamics $\left(U_{\text {approximate }}\right)$ and from the NTU method $\left(U_{N T U}\right)$ for air inlet temperatures of $33^{\circ} \mathrm{C}$ and $150{ }^{\circ} \mathrm{C}$. 


\subsection{Performances of the Heat Exchanger Integrated to The Solid Biomass-Fuelled Micro-CHP System}

The experimental performances of the heat exchanger are detailed in Table 4. The heat exchanger hot fluid effectiveness and cold fluid effectiveness are low and may be enhanced by using pressurized air as considered in the theoretical energetic study [15], or by increasing the heat exchange surface area.

Table 4. Experimental performances of the heat exchanger for air volume flow rate of $10 \mathrm{Nm}^{3} / \mathrm{h}$ and air inlet temperature of $150^{\circ} \mathrm{C}$.

\begin{tabular}{lc}
\hline Parameter & Value \\
\hline$T_{\text {air,in }}$ & $150^{\circ} \mathrm{C}$ \\
$T_{\text {air,ex }}$ & $336^{\circ} \mathrm{C}$ \\
$T_{\text {gas,in }}$ & $962^{\circ} \mathrm{C}$ \\
$T_{\text {gas }, x}$ & $897{ }^{\circ} \mathrm{C}$ \\
$R_{c}$ & 0.354 \\
$R_{h}$ & 2.826 \\
$N T U_{\text {air }}$ (on the side of air) & 0.271 \\
$N T U_{\text {gas }}$ (on the side of flue gas) & 0.096 \\
Effectiveness $E_{\text {air }}$ & $22.7 \%$ \\
Effectiveness $E_{\text {gas }}$ & $8.1 \%$ \\
Exchange surface area on the side of air $A_{\text {air }}$ & $0.22 \mathrm{~m}$ \\
Thermal power transferred & $719 \mathrm{~W}$ \\
Exergetic effectiveness $E_{e_{c}}$ (on the side of air) & $13.8 \%$ \\
Exergetic effectiveness $E_{\text {ex }_{h}}$ (on the side of flue gas) & $10.5 \%$ \\
Exergetic efficiency & $56.5 \%$ \\
\hline
\end{tabular}

\subsection{Exergetic Flux and Exergy Destruction in the Micro-CHP System}

The exergetic efficiency of the global solid biomass-fuelled micro-CHP system is written:

$$
\eta_{e x, \mu C H P}=\frac{\dot{E} x_{c o g e}^{\dot{W}}+\dot{E} x_{c o g e}^{a i r, e x}+\dot{E} x_{H w}^{g a s, e x}+\dot{E} x_{H w}^{\text {water,ex }}}{\dot{E} x_{c o m b}^{a i r, i n}+\dot{E} x_{c o m b}^{b i o m a s s}+\dot{E} x_{c o g e}^{a i r, i n}+\dot{E} x_{H w}^{w a t e r, i n}}
$$

This definition corresponds to a maximum theoretical exergetic efficiency and reaches the value of $25.2 \%$, with the following main data of the system:

- For the gas-water heat exchanger (Hw): mass flow rate of water $=0.5 \mathrm{~kg} / \mathrm{s}$, mass flow rate of gas $=0.022 \mathrm{~kg} / \mathrm{s}$, water inlet temperature $=60^{\circ} \mathrm{C}$, water outlet temperature $=80^{\circ} \mathrm{C}$, gas outlet temperature $=180^{\circ} \mathrm{C}$.

- For the combustion chamber (comb): mass flow rate of pellet $=0.002 \mathrm{~kg} / \mathrm{s}$, mass flow rate of air $=0.020 \mathrm{~kg} / \mathrm{s}$, air inlet temperature $=20^{\circ} \mathrm{C}$, outlet gas temperature $=800^{\circ} \mathrm{C}$.

- For the Ericsson engine (coge): mass flow rate of air $=0.0019 \mathrm{~kg} / \mathrm{s}$, air inlet temperature $=20^{\circ} \mathrm{C}$, air outlet temperature $=198^{\circ} \mathrm{C}$.

The Sankey diagram of the exergetic fluxes associated to the micro-CHP system is presented in Figure 11. The arrows associated to exergy destruction represent both recoverable and unrecoverable exergetic fluxes. The highest exergy destruction is linked to solid biomass combustion. The exergy destruction in the heat exchanger supplying the Ericsson engine is low, when compared to the exergy destruction of the water heat exchanger, mainly due to the difference in thermal power exchanged in both heat exchangers. A fraction of the exergy destruction, linked to heat transfers at the micro-CHP components walls, may be avoided by insulating the components that might enhance the exergetic performances of the system. However, from the present study, it is not possible to estimate the fraction of unrecoverable exergy (associated to entropy generation) in the exergy destruction. 


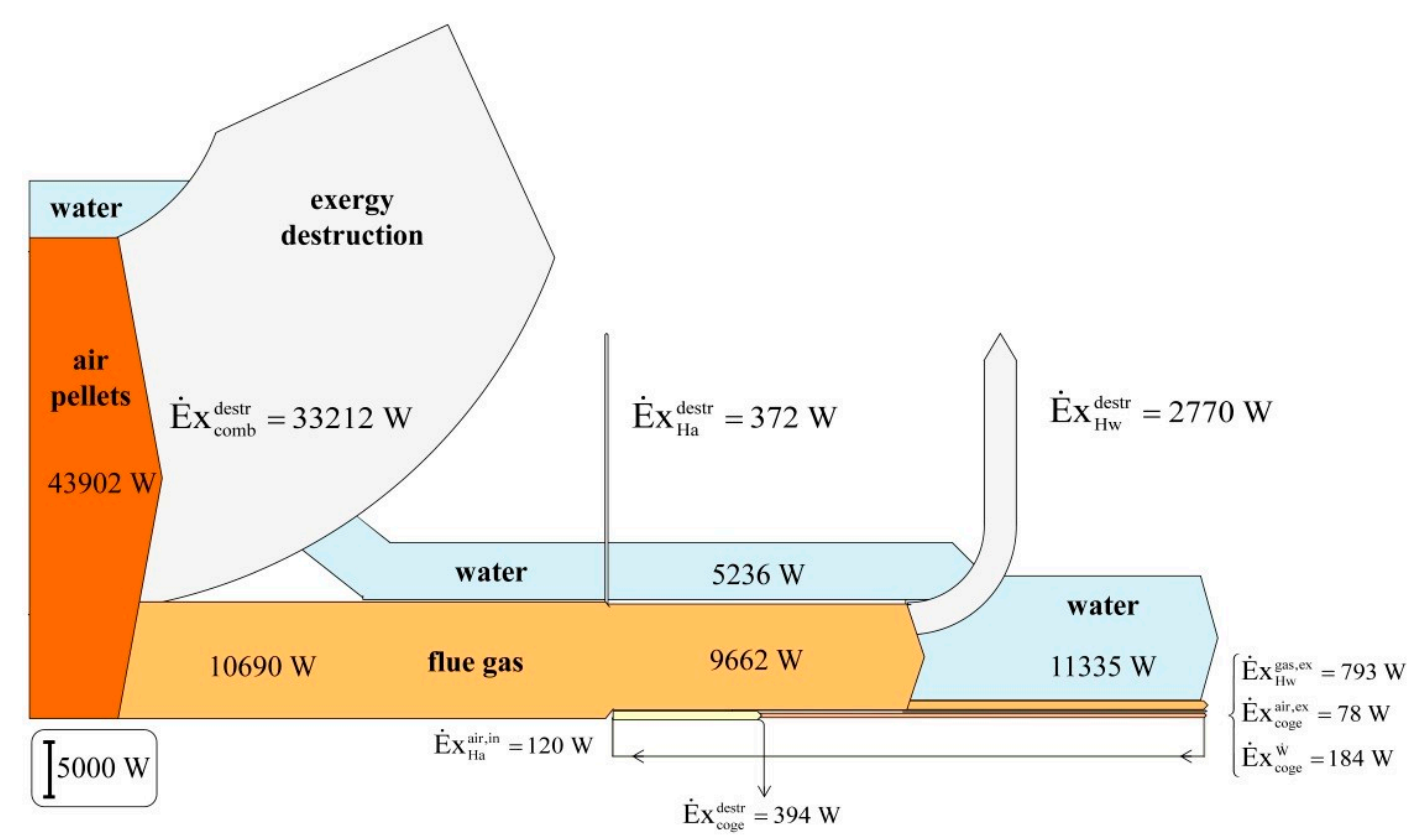

Figure 11. Sankey diagram of the exergetic fluxes in the solid biomass-fuelled micro-CHP system.

\section{Conclusions}

To study a heat exchanger intended for the heat supply of an Ericsson engine associated to a solid biomass-fuelled micro-CHP system, an experimental test bench is implemented, with the measurement of air mass flow rate and temperatures of inlet and exhaust air, flue gas and wall. The objective of the paper is firstly to validate an energetic model of the heat transfer crossing the heat exchanger inserted in the micro-CHP unit with experimental results, and secondly to present an exergy analysis of the heat exchanger. The energetic model is based on a NTU method and the exergy fluxes associated to the heat exchanger are modelled, including the estimation of the specific chemical exergy of solid biomass fuel. The exergy and energy analysis are complementary. To optimize the micro-CHP system, the exergy analysis is necessary to calculate the destructed exergetic fluxes for each component, as the heat exchanger located inside the boiler. To complete the estimation of the heat exchanger exergetic efficiciency which is the ratio between produced exergy and resource exergy, a new exergetic parameter is introduced: the exergetic effectiveness, allowing a comparison between the real and the ideal heat exchanger considering the Second Law of Thermodynamics. The results of the experimental tests are compared with the energetic study and corroborate the theoretical results previously obtained [15]. The convection phenomenon between air and heat exchanger wall is the first limit to the global heat transfer. The comparison of experimental global heat transfer coefficients evaluated with an energy balance and with the NTU model shows that the NTU method is adapted to model heat exchangers including radiation from flue gas. Concerning the energy and exergy analysis of the heat exchanger, compared with the air side, the effectiveness and exergetic effectiveness on the flue gas side are lower because of the low energy quantity transferred to air regarding the high energy quantity of flue gas. They may be enhanced by using pressurized air as considered in the theoretical energetic study [15], or by increasing the heat exchange surface area. The evaluation of the performances of the heat exchanger is more objective when using exergetic performances than the usual effectiveness from NTU method (performance with energetic aspect) because the entropy generated when the temperatures of the fluids change is considered in the calculations. The evaluation of the exergetic fluxes and the exergy destruction in the micro-CHP system shows that the combustion of solid biomass presents the highest exergy destruction. The heat exchanger supplying the Ericsson engine has a low impact on the total exergy destruction of the system, because of the low heat exchanged. A fraction of the 
exergy destruction, linked to heat transfers at the micro-CHP components walls, may be avoided by insulating the components that might enhance the exergetic performances of the system.

Acknowledgments: This work has been performed in the framework of the regional project Sylwatt, carried out in partnership with the laboratories LAMIH (Valenciennes, France), PC2A (Lille, France), CCM (Dunkerque, France). A financial support has been provided by the Région Nord-Pas-de-Calais, by the French National Association of Research and Technology ANRT (doctoral scholarship) and by the company Enerbiom. The authors are very grateful to all the persons involved in the setting up of the heat exchanger test bench and in the experimental tests. They thank in particular Sébastien Coupeaux and Annick Many (UVHC), Marc Lippert and Jesse Schiffler (LAMIH), Federico Spoldi (LAMIH).

Author Contributions: This study synthetizes the research work investigated by Marie Creyx, Eric Delacourt, Céline Morin, Sylvain Lalot and Bernard Desmet. The energetic and exergetic models were developed by Marie Creyx. Experimental characterization was performed by Marie Creyx and Eric Delacourt. Sylvain Lalot developed the NTU method. All authors analyzed the results, wrote and revised the paper. All authors have read and approved the final manuscript.

Conflicts of Interest: The authors declare no conflict of interest.

\section{References}

1. Crema, L.; Alberti, F.; Bertaso, A.; Bozzoli, A. Development of a pellet boiler with Stirling engine for m-CHP domestic application. Energy Sustain. Soc. 2011, 1, 1-11. [CrossRef]

2. Thiers, S.; Aoun, B.; Peuportier, B. Experimental characterization, modeling and simulation of a wood pellet micro-combined heat and power unit used as a heat source for a residential building. Energy Build. 2010, 42, 896-903. [CrossRef]

3. Biedermann, F.; Carlsen, H.; Schöch, M.; Obernberger, I. Operating experiences with a small-scale CHP pilot plant based on a $35 \mathrm{~kW}_{\mathrm{el}}$ hermetic four cylinder Stirling engine for biomass fuels. In Proceedings of the 11th International Stirling Engine Conference, Rome, Italy, 19-21 November 2003; pp. 19-21.

4. Podesser, E. Electricity production in rural villages with a biomass Stirling engine. Renew. Energy 1999, 16, 1049-1052. [CrossRef]

5. Qiu, K.; Hayden, A.C.S. Integrated thermoelectric and organic Rankine cycles for micro-CHP systems. Appl. Energy 2012, 97, 667-672. [CrossRef]

6. Alanne, K.; Laukkanen, T.; Saari, K.; Jokisalo, J. Analysis of a wooden pellet-fueled domestic thermoelectric cogeneration system. Appl. Therm. Eng. 2014, 63, 1-10. [CrossRef]

7. Creyx, M.; Delacourt, E.; Morin, C.; Desmet, B.; Peultier, P. Energetic optimization of the performances of a hot air engine for micro-CHP systems working with a Joule or an Ericsson cycle. Energy 2013, 49, 229-239. [CrossRef]

8. Bell, M.A.; Partridge, T. Thermodynamic design of a reciprocating Joule cycle engine. Proc. Inst. Mech. Eng. Part A 2003, 217, 239-246. [CrossRef]

9. Al-Attab, K.A.; Zainal, Z.A. Performance of high-temperature heat exchangers in biomass fuel powered externally fired gas turbine systems. Renew. Energy 2010, 35, 913-920. [CrossRef]

10. Gaderer, M.; Gallmetzer, G.; Spliethoff, H. Biomass fired hot air gas turbine with fluidized bed combustion. Appl. Therm. Eng. 2010, 30, 1594-1600. [CrossRef]

11. McDonald, C.F. Recuperator considerations for future higher efficiency microturbines. Appl. Therm. Eng. 2003, 23, 1463-1487. [CrossRef]

12. El-Ehwany, A.A.; Hennes, G.M.; Eid, E.I.; El-Kenany, E. Experimental investigation of the performance of an elbow-bend type heat exchanger with a water tube bank used as a heater or cooler in alpha-type Stirling machines. Renew. Energy 2011, 36, 488-497. [CrossRef]

13. Carlsen, H.; Marinitsch, G.; Schöch, M.; Obernberger, I. Development of a hot heat exchanger and a cleaning system for a $35 \mathrm{~kW}$ hermetic four cylinder Stirling engine for solid biomass fuels. In Proceedings of the 12th International Stirling Engine Conference and Technology Exhibition, Durham, UK, 7-9 September 2005.

14. Bonnet, S.; Alaphilippe, M.; Stouffs, P. Energy, exergy and cost analysis of a micro-cogeneration system based on an Ericsson engine. Int. J. Therm. Sci. 2005, 44, 1161-1168. [CrossRef]

15. Creyx, M.; Delacourt, E.; Morin, C.; Desmet, B.; Peultier, P. Modelling of the heat transfers in a flue gas-air heat exchanger implanted in a solid biomass fuelled micro-combined heat and electrical power system. In Proceedings of the Eurotherm Seminar No 96, Brussels, Belgium, 17-18 September 2013. 
16. Lalot, S. The NTU-Effectiveness Method; Nova Science Publishers: New York, NY, USA, 2011.

17. Tessé, L.; Lamet, J.-M. Radiative transfer modeling developed at Onera for numerical simulations of reactive flows. Aerosp. Lab 2011, 2, 1-19.

18. Rivière, P.; Soufiani, A. Updated band model parameters for $\mathrm{H}_{2} \mathrm{O}, \mathrm{CO}_{2}, \mathrm{CH}_{4}$ and $\mathrm{CO}$ radiation at high temperature. Int. J. Heat Mass Transf. 2012, 55, 3349-3358. [CrossRef]

19. Chase, M.W., Jr., Ed.; NIST-JANAF Themochemical Tables, Fourth Edition. J. Phys. Chem. Ref. Data Monogr. 1998, 9, 1-1951.

20. Song, G.; Xiao, J.; Zhao, H.; Shen, L. A unified correlation for estimating specific chemical exergy of solid and liquid fuels. Energy 2012, 40, 164-173. [CrossRef]

21. Al-Sulaiman, F.A.; Hamdullahpur, F.; Dincer, I. Greenhouse gas emission and exergy assessments of an integrated organic Rankine cycle with a biomass combustor for combined cooling, heating and power production. Appl. Therm. Eng. 2011, 31, 439-446. [CrossRef]

22. Szargut, J. Exergy Method: Technical and Ecological Applications; WIT Press: Southampton, UK; Boston, MA, USA, 2005.

23. Szargut, J.; Morris, D.R.; Steward, F.R. Exergy Analysis of Thermal, Chemical, and Metallurgical Processes; Hemisphere: New York, NY, USA, 1988.

24. Shieh, J.H.; Fan, L.T. Estimation of Energy (Enthalpy) and Exergy (Availability) Contents in Structurally Complicated Materials. Energy Sources 1982, 6, 1-46. [CrossRef]

25. Wu, S.Y.; Yuan, X.F.; Li, Y.R.; Xiao, L. Exergy transfer effectiveness on heat exchanger for finite pressure drop. Energy 2007, 32, 2110-2120. [CrossRef]

26. Lalot, S.; Florent, P.; Lang, S.K.; Bergles, A.E. Flow maldistribution in heat exchangers. Appl. Therm. Eng. 1999, 19, 847-863. [CrossRef]

27. Bergman, T.L.; Lavine, A.S.; Incropera, F.P.; DeWitt, D.P. Fundamentals of Heat and Mass Transfer; Wiley: New York, NY, USA, 2011.

(C) 2016 by the authors; licensee MDPI, Basel, Switzerland. This article is an open access article distributed under the terms and conditions of the Creative Commons Attribution (CC-BY) license (http://creativecommons.org/licenses/by/4.0/). 